\title{
Pain pressure thresholds for evaluating myofascial pain in the equine brachiocephalicus muscle
}

\author{
Calatayud-Bonilla M. ${ }^{1}$ Resano-Zuazu M. ${ }^{1}$ Segura-Ortí E. ${ }^{1}$ \\ ${ }^{1}$ Universidad CEU Cardenal Herrera, Universidades CEU, Valencia, \\ Spain
}

Rev Fisioter Invasiva 2019;2:114

\begin{abstract}
\section{Keywords}

- pressure algometer

- trigger point

- myofascial pain

- equine

Introduction Myofascial pain is one of the most common musculoskeletal pathologies in humans, with the presence of myofascial trigger points (MTrPs). A MTrP is defined as a hyperirritable nodule in a taut band of musculoskeletal fibers. The pain pressure threshold is a tool for the assessment of pain used in humans with proven reliability, however there is no evidence of the same in the study of MTrPs in horses. Aims The aim of this study was to evaluate the reliability of the measurement of pressure pain sensitivity in horses with MTrPs in the brachiocephalicus muscle. A second aim was to calculate the minimum detectable change (MDC) for this result. Material and Methods Twenty horses were evaluated, aged between five and fifteen years old. All without pathology or previous pharmacological treatment. The cranial angle of the scapula was taken as the anatomic reference. A first evaluator, whose reliability was already confirmed, performed a manual palpation of the distal aspect of the brachiocepalicus muscle. A MTrP was located in all animals included in the study. The anatomic reference and the MTrP were marked. The pain pressure threshold of the MTrP was measured using a pressure algometer (Wagner Instruments, EE.UU., $\mathrm{kg} / \mathrm{cm} 2$ ). The same evaluator applied the tip of the algometer parallel to the neck and transversal to the muscle fibers, gradually increasing pressure until the 'jump sign' or facial expressions of pain were detected by a second operator who also recorded the measurements. The measurements were repeated consecutively twice in this manner. The first operator was blind to the measurements. The intraclass correlation index (ICC) was calculated to evaluate reliability.

Results The mean thresholds of pain pressure sensitivity registered for the first and second measurement were $3.29(1.0) \mathrm{kg} / \mathrm{cm} 2$ and $3.31(0.9) \mathrm{kg} / \mathrm{cm} 2$. The ICC was 0.86 (95\% Cl: 0.68 to 0.95$)$. The MDC was $0.9 \mathrm{~kg} / \mathrm{cm} 2$ (95\% Cl: 0.6 to 1.4$)$.

Conclusions Acceptable reliability was found for the measurement of the pain pressure threshold in horses with MTrPs in the brachiocephalicus muscle.
\end{abstract}

DOI https://doi.org/ $10.1055 / \mathrm{s}-0039-3401885$ ISSN 2386-4591.
Copyright @ 2019 by Thieme Revinter Publicações Ltda, Rio de Janeiro, Brazil

License terms

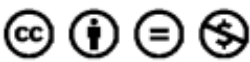

